\title{
Altmetria ou métricas alternativas: conceitos e principais características
}

\section{Altmetrics or alternative metrics: concepts and key features}

\author{
lara Vidal Pereira de Souza ${ }^{1}$ \\ ${ }^{1}$ Programa de Pós-Graduação em Ciência da Informação IBICT-UFRJ, Rio de Janeiro, RJ, Brasil
}

Autor para correspondência/Mail to: Iara Vidal Pereira de Souza iaravidalps@gmail.com

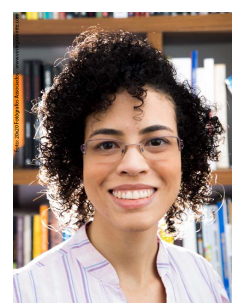

Iara Vidal Pereira de Souza é Bacharel em Biblioteconomia pela Universidade Federal do Estado do Rio de Janeiro (Unirio, 2004) e Mestre em Ciência da Informação pela Universidade Federal Fluminense (UFF, 2014). Atualmente cursa Doutorado em Ciência da Informação no Programa de Pós-Graduação em Ciência da Informação do Instituto Brasileiro de Informaçao em Ciência e Tecnologia convênio com a Universidade Federal do Rio de Janeiro (IBICT-ECO/UFRJ). Currículo Lattes: http://lattes.cnpq.br/1772141226569944 | ORCID: orcid.org/0000-0003-1360-6127

\section{Resumo}

Apresentam-se os conceitos e características das métricas alternativas (ou altmetria, em português), com especial destaque para a relação destas com as métricas tradicionais e potenciais riscos de manipulação de dados. Discutem-se os desafios para tais métricas e as ferramentas disponíveis para tal contagem

Palavras-chave: Altmetria; Redes sociais; Bibliometria; Infometria

\section{Abstract}

This interview presents the concepts and characteristics of the alternative metrics (or altmetria, in portuguese), emphasising their relationship to the traditional metrics and the potential for hazards, mainly artificial data manipulation. Discusses the challenges for such metrics and the tools available.

Keywords: Altmetrics; Social networks; Bibliometrics, Infometrics

\section{O que são altmetrics?}

Altmetrics ou métricas alternativas são indicadores da comunicação científica baseados na web social. Não se trata de uma medida única, mas de um conjunto de métricas muito diversos - por exemplo, quantas vezes um artigo foi compartilhado numa rede social como o Twitter, ou salvo em um gerenciador de referências como o Mendeley. O termo altmetrics, traduzido em português como altmetria, também se refere aos estudos sobre esses indicadores. Suas origens estão ligadas ao Altmetrics Manifesto, publicado em 2010 e disponível no site altmetrics.org.

\section{Quais as vantagens de uso das métricas alternativas em relação aos métodos ou técnicas bibliométricas e/ou cientométricas tradicionais?}

Com as métricas alternativas é possível ter informações sobre o alcance e o uso de trabalhos científicos que são muito difíceis ou até impossíveis de obter por meio de métodos tradicionais como a análise de citação. A citação é um indicador muito importante, sem dúvida, mas ela só conta uma parte da história. A utilidade de um trabalho científico não se resume às citações formais: ele pode servir para um professor preparar sua aula, pode ajudar médicos em decisões clínicas, e muitos outros usos que não geram citações. A grande vantagem da altmetria não é substituir as medidas tradicionais, mas ajudar a construir um quadro mais completo sobre o impacto da ciência.

\section{Quais os desafios relacionados ao uso das métricas alternativas?}

Os desafios são muitos, mas acho que é possível resumi-los em dois pontos principais. Um é a questão técnica: a falta de padrões para coleta e tratamento das métricas alternativas. Por exemplo, o uso de identificadores digitais como o DOI (para itens) e o ORCID (para autores) seria fundamental para facilitar a coleta de dados altmétricos. O outro, que tem relação com o primeiro, é teórico: ainda não sabemos exatamente o que significam esses dados. Como falei no início, são muitos indicadores possíveis, e é difícil estabelecer relações entre eles. Qual a relação entre um tweet e um post no Facebook? Um post de blog tem mais valor que um leitor do Mendeley? Um 
artigo compartilhado 1000 vezes é melhor que um artigo compartilhado 100 vezes? Não temos respostas para essas perguntas, e creio que é possível que essas respostas variem de acordo com o contexto. Já sabemos que os padrões de citação variam de disciplina para disciplina, creio que algo semelhante deve acontecer com as métricas alternativas. É muito importante realizar estudos altmétricos em diferentes contextos se quisermos chegar a uma compreensão mais ampla desses indicadores.

\section{Quais as principais ferramentas e indicadores da atualidade para altmetrics?}

As ferramentas principais são quatro: PLOS Article-Level Metrics, Altmetric, Plum Analytics e ImpactStory. A PLOS ALM (article-level-metrics.plos.org), de 2009 (anterior ao próprio Altmetrics Manifesto), é desenvolvida pela Public Library of Science. Inicialmente só tinha dados dos artigos publicados em periódicos da própria PLOS, mas já está disponível também para outros editores, instituições e publicações como um aplicativo de código aberto, o Lagotto. A Altmetric (http://www.altmetric.com), vinculada à empresa britânica Digital Science é talvez a mais conhecida entre todas as ferramentas. Está presente na SCOPUS, na SciELO, na Nature e em muitos outros periódicos e bases. Sua grande contribuição é o Altmetric Donut: um anel colorido em que cada cor representa uma fonte altmétrica diferente. A Plum Analytics (http://www.plumanalytics.com), vinculada à EBSCO, oferece seus serviços para instituições como universidades e agências de fomento; enquanto a ImpactStory (http://impactstory.org) está voltada para pesquisadores individuais.

Em matéria de indicadores, os mais promissores parecem ser os gerenciadores eletrônicos de referências, em especial o Mendeley. Estudos indicam que eles podem ser usados para prever que trabalhos devem acumular mais citações. O Twitter também tem sido bastante estudado, assim como os blogs que discutem trabalhos científicos.

\section{Sou editor/a de revista e gostaria de implementar altmetrics, como faço?}

Quem usa o Open Journal System (OJS, ou SEER na versão brasileira) para gerenciar sua revista pode procurar pelo plugin da PLOS Article-Level Metrics disponível para esta plataforma. A Rede SciELO tem uma parceria com a Altmetric e revistas naquela plataforma podem incluir o donut em suas páginas. Outras opções são procurar pelos serviços (pagos) da Altmetric, testar o Lagotto, software livre da PLOS, ou ainda coletar dados por conta própria utilizando as APIs gratuitas de serviços como Twitter, Facebook e Mendeley. Considere adotar um identificador digital para seus artigos caso ainda não o tenha feito, isso facilita muito a coleta de dados seja qual for a ferramenta escolhida.

\section{As altmetrics podem ser passíveis de manipulação tais como a criação de impressões ou clicks artificiais? Caso sim há formas de prevenir essa manipulação?}

A princípio, sim. Não existem casos registrados, até onde eu sei, mas a possibilidade é real. É razoável imaginar que esse tipo de manipulação se torne mais recorrente (assim como já acontece com fatores de impacto e contagens de citação), caso as agências de fomento passem a utilizar dados altmétricos em suas avaliações. Mas a prevenção e o controle são possíveis, e já são exercidos em outros campos. Na área comercial e na política, por exemplo, há quem tente aumentar artificialmente suas curtidas e/ou o número de seguidores utilizando bots, perfis falsos, e estratégias semelhantes, mas há ferramentas que identificam essas fraudes. Poderemos aplicar estas técnicas também no âmbito científico.

\section{Algumas revistas e/ou agregadores, tais como a Nature e o SciELO, têm utilizado as altmetrics de forma complementar às métricas já consolidadas. É possível apontar uma direção provável de uso conjunto desses dados?}

Para as revistas e agregadores científicos, creio que uma aplicação possível da altmetria é no marketing. Entender que plataformas da web social os leitores da sua revista preferem e que tipo de conteúdo recebe mais atenção pode ajudar no planejamento dos editores. Claro que não estou falando de aceitar ou rejeitar conteúdos baseados no que pode ou não "bombar" na web - a ideia aqui é conhecer sua audiência, e pensar em estratégias para alcançar mais pessoas. 
Como citar esta entrevista (APA):

Souza, I. V. P. (2015). Altmetria ou métricas alternativas: conceitos e principais características. AtoZ: novas práticas em informação e conhecimento, 4(2), 58 - 60. Recuperado de: http://dx.doi.org/10.5380/atoz.v4i2 .44554 